\title{
MOEDAS VOTIVAS: UM ESTUDO DAS MOEDAS DO IMPERADOR GRACIANO (367-383 D.C.)
}

\author{
Janira Feliciano Pohlmann ${ }^{1}$
}

Recebido em: 22/11/2021

Aprovado em: 28/12/2021

\begin{abstract}
Resumo: Neste artigo, apresento uma análise sobre as moedas votivas do imperador Graciano. Observo que meus argumentos são elaborados, sobretudo, pelo ponto de vista da História, visto ser esta a minha formação. A partir da moeda 163998 do acervo do Museu Histórico Nacional do Rio de Janeiro, batida sob o governo de Graciano (367-383 d.C.), optei por analisar a tradição da cunhagem destas moedas que celebravam acontecimentos do Império romano. Desejava conhecer os elementos que compunham esta homenagem organizada suscintamente em pequenas peças metálicas. Ao numerário 163998, uni outros documentos monetários para compreender melhor o contexto estudado e alcançar o objetivo proposto de examinar uma importante tradição romana. Esclareço, ainda, que esta investigação foi levada a cabo através da metodologia dos estudos iconográficos, significativos para o entendimento de determinadas ideias disseminadas nas sociedades romanas. Por meio destes estudos, é perceptível que, além de serem elementos com valor de troca, as moedas na antiguidade romana eram instrumentos de poder que auxiliavam na manutenção do poder imperial.
\end{abstract}

Palavras-chave: Imperador Graciano; Moedas votivas; Tradição; Iconografia; Poder imperial.

\section{MONEDAS VOTIVAS: ESTUDIO DE LAS MONEDAS DEL EMPERADOR GRACIANO (367-383 D.C.)}

Resumen: En este artículo, presento un análisis de las monedas votivas del emperador Graciano. Observo que mis argumentos están elaborados, sobre todo, desde el punto de vista de la Historia, ya que ésta es mi formación. Partiendo de la moneda 163998 de la colección del Museu Histórico Nacional do Rio de Janeiro, acuñada bajo el mandato de Graciano (367-383 d.C.), he optado por analizar la tradición de la acuñación de estas monedas que celebraban acontecimientos del Imperio Romano. Quería conocer los elementos que componían este homenaje, que estaba organizada en pequeñas piezas de metal. Al numeral 163998, uní otros documentos monetarios para comprender mejor el contexto estudiado y alcanzar el objetivo propuesto de examinar una importante tradición romana. Aclaro también que esta investigación se llevó a cabo mediante la metodología de los estudios iconográficos, significativa para la comprensión de ciertas ideas difundidas en las sociedades romanas. A través de estos estudios, se percibe que, además de ser elementos con valor de cambio, las monedas en la antigüedad romana eran instrumentos de poder que ayudaban a mantener el poder imperial.

\footnotetext{
${ }^{1}$ Pós-doutoranda em História da Universidade Federal do Paraná. Membro do Núcleo de Estudos Mediterrânicos (NEMED-UFPR) e do Grupo do Laboratório de Estudos ,sobre o Império Romano (G.LEIR-UNESP/Franca). Email: janirapo@yahoo.com.br. Orcid: https://orcid.org/0000-0002-4204-2853
} 
Palabras clave: Emperador Graciano; Monedas votivas; Tradición; Iconografía; Poder imperial.

\title{
VOTIVE COINS: A STUDY OF THE COINS OF EMPEROR GRACIAN (367-383 A.D.)
}

\begin{abstract}
In this article, I present an analysis of the votive coins of Emperor Gratian. I note that my arguments are elaborated, above all, from the point of view of History, since this is my formation. Starting from coin 163998 of the collection of the Museu Histórico Nacional do Rio de Janeiro, struck under Gratian (367-383 AD), I chose to analyze the tradition of the minting of these coins that celebrated events of the Roman Empire. I wanted to know the elements that made up this tribute, which was organised in small metal pieces. To the numeral 163998, I joined other monetary documents in order to better understand the studied context and to reach the proposed objective of examining an important Roman tradition. I also clarify that this research was carried out through the methodology of iconographic studies, significant for the understanding of certain ideas disseminated in Roman societies. Through these studies, it is perceptible that, besides being elements with exchange value, coins in Roman antiquity were instruments of power that helped maintain imperial power.
\end{abstract}

Keywords: Emperor Gratian; Votive coins; Tradition; Iconography; Imperial power.

\section{Introdução: uma historiadora e um estudo sobre antigas moedas romanas}

Inicio este texto com um esclarecimento: sou uma historiadora que encontrou na Arqueologia uma ciência amiga com a qual dialogo para compreender melhor os aspectos político-administrativos e culturais de uma sociedade romano-ocidental que existia entre o final do século IV d.C. e princípio do século V d.C. ${ }^{2}$ Reconheço o papel central da Arqueologia em todas as formas de história documental (Funari, Hall, Jones, 1999, p. 7), por isso, fiz desta ciência minha parceira na pesquisa histórica, a fim de conhecer elementos que estavam ausentes dos textos antigos ou para ter um panorama mais amplo do que aquele registrado textualmente.

Meus questionamentos, neste artigo, partiram de um documento material: uma moeda do imperador Graciano que faz parte do acervo do Museu Histórico Nacional do Rio de Janeiro (MHN-RJ). Neste museu, a moeda é identificada pela numeração 163998 e é uma das trinta e duas moedas de Graciano que compõem a coleção desta instituição. Trata-se de uma moeda votiva. Ao examinar este numerário, perguntei-me até que ponto Graciano se vinculou a uma tradição para ordenar a cunhagem desta moeda. Havia algo de original neste documento? Que mensagem Graciano teria elaborado e cunhado nas moedas votivas?

\footnotetext{
${ }^{2}$ Neste artigo, as datas referem-se a período da Era Comum, por isso, doravante, oprimirei a abreviação "d.C.". As exceções serão marcadas pela abreviação "a.C.".
} 
Uma vez que decidi estudar uma moeda, rapidamente atrelei minhas pesquisas à Numismática e entre os métodos de análise desta ciência optei pelo iconográfico, o qual se ocupa das representações figuradas das moedas, estendendo-se para o estudo das legendas, letras e símbolos. Desta forma, o estudo iconográfico de uma moeda (ou de uma série) referese à análise do conjunto das gravações contidas no documento, ou seja, do tipo monetário.

A arqueóloga Maria Beatriz Borba Florenzano afirma que, no caso das moedas, além de identificar sua autoridade emissora, "imagens, inscrição, formato devem ser interpretados no seu conjunto" (Florenzano, 2001, p. 64), nesta conjuntura, o estudo iconográfico é imprescindível. Vagner Carvalheiro Porto (2007, p. 95) considera a abordagem iconográfica uma ferramenta de trabalho que permite aos pesquisadores compreenderem diferentes esferas da sociedade, como a política, a propaganda e a religião greco-romana. Quando aplicada ao estudo de moedas de Graciano, noto que esta metodologia permite a identificação de cultos religiosos, da autoridade emissora do numerário (imperador) e de vinculações com elementos tradicionais, é possível, também, examinar a legitimação do governante. Com exceção das alusões a cultos religiosos, as moedas selecionadas para este artigo me permitem observar os demais elementos mencionados.

Noto que, na época imperial, as moedas romanas eram amplamente utilizadas para o pagamento do soldo dos soldados e no comércio. Então, estas pequenas peças de ouro, prata ou bronze carregavam as mensagens ali gravadas pela vastidão do Império e para fora dele. Segundo Alain Jean Costilhes, as legendas das moedas imperiais tinham uma função pois identificavam a autoridade emissora e levavam "uma mensagem que a autoridade queria transmitir" (Costilhes, s/d., p. 48). É um erro, portanto, analisar uma moeda greco-romana pelo ponto de vista econômico e capitalista sob o qual são produzidas as moedas na atualidade. Além do valor de troca que as moedas antigas continham, elas também tinham valor para a política imperial, permitindo que o nome do imperador, suas vinculações religiosas e culturais e acontecimentos significativos para o Império fossem conhecidos por mais pessoas e em terras distantes de onde o imperador estava. Neste ínterim, a análise das moedas, levada a cabo através da metodologia dos estudos iconográficos, me possibilita observar uma das formas de legitimação do poder imperial, uma vez que, durante o Império, houve o avanço do culto à figura do governante e estas peças metálicas eram excelentes espaços para a anunciação deste ritual.

Percebo que, em um Império extenso como o romano, nem todas as pessoas tinham a oportunidade de ver o imperador. Então, os tipos gravados nos numerários recordavam a todos súditos, mesmo aos mais longínquos, a supremacia do poder daquele personagem que tinha seu 
busto e seu nome registrados nas moedas. Neste ínterim, os numerários também eram instrumentos de propagação de um discurso que alimentava o poder imperial. Eram, portanto, instrumentos de poder, essenciais para a construção e para a manutenção da liderança dos imperadores romanos. E é especialmente sob este ponto de vista que leio os anversos e os reversos estes documentos.

\section{As moedas votivas de Graciano}

Conforme esclarecido, meus estudos para este artigo tiveram como ponto de partida uma moeda votiva do imperador Graciano:
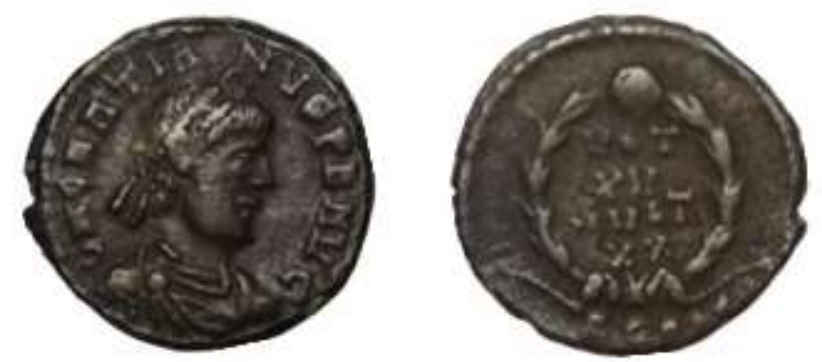

Imagem 1. Número de localização no acervo do MHN-RJ: 163998 Bronze, AE3. Oficina desconhecida, 381/382 d.C.

Anv.: D N GRATIA_NVS P F AVG. Busto com diadema de pérolas, drapeado e encouraçado de Graciano, à direita.

Rev.: VOT/XV/MVLT/XX dentro da coroa de louros; em baixo, letras ilegíveis

Referência: Acervo pessoal; julho/2017.

No reverso deste documento, destaca-se a legenda "VOT/XV/MVLT/XX" que abrevia a mensagem latina "votis quindecennalibus multis vicennalibus". Em português: "votos pelo aniversário de quinze anos [do augusto como governante], que chegue aos vinte". Em 367, Graciano foi aclamado augusto pelas legiões quando acompanhava seu pai, o imperador Valentiniano I (364-375), em campanhas militares. Logo, é possível se identificar aproximadamente o ano em que esta moeda foi cunhada: 381 ou 382. Tradicionalmente, as moedas votivas começavam a ser cunhadas um ano antes do fato que celebravam e esta cunhagem se estendia até a data comemorada. Sendo assim, 381 corresponderia a este período que antecipava os quinze anos de Graciano como augusto e 382, o ano em que acontecia o quindénio deste imperador. 
Observadas estas informações, indaguei-me sobre a tradição a qual Graciano vinculouse quando ordenou a cunhagem deste numerário. Emitir moedas para celebrar os aniversários de governos era uma práxis romana. Durante a tetrarquia, Diocleciano (284-305) e Maximiano (286-305; 306-310) comemoraram seus aniversários de vinte anos como augusto. As moedas provavelmente foram lançadas em 303/4?, no caso de Diocleciano, e 305/6?, no caso de Maximiano. Poucos anos separavam um numerário do outro, mas ambos os documentos traziam em seus reversos a legenda: VOT/XX (Votis vicennalibus), ou seja, "votos pelos vintes anos de governo".
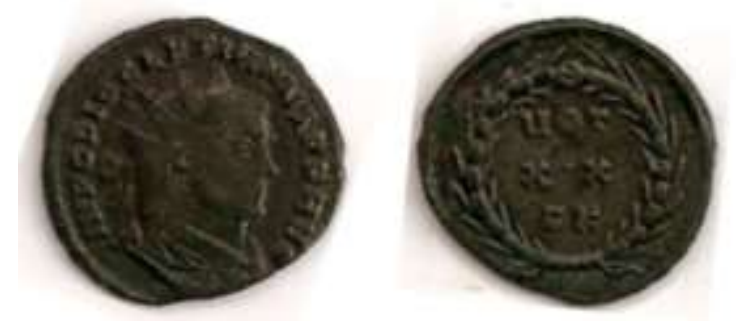

Imagem 2. Moeda de Diocleciano. Comemoração de seus vinte anos como augusto.

Bronze, 303/304 d.C.

Anv.: IMP C VAL DIOCLETIANUS P F AVG. Busto com coroa radiada, drapeado e encouraçado de Diocleciano, à direita.

Rev.: VOT/XX/FK dentro de coroa de louro.

Referência: http://www.coinproject.com/coin_detail.php?coin=287491. Acesso em: 09/11/2021.

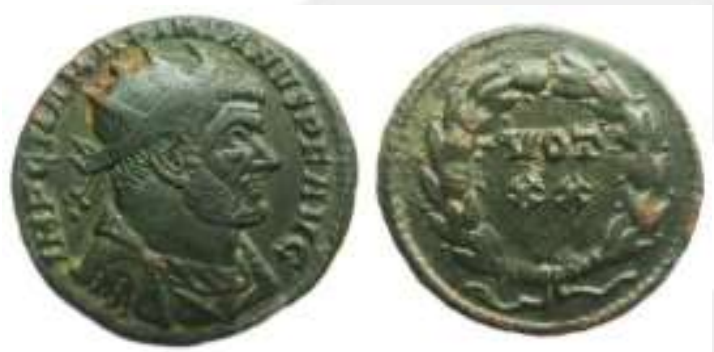

Imagem 3. Moeda de Maximiano. Comemoração de seus vinte anos como augusto.

Bronze, 305/306 d.C.

Anv.: IMP C M A MAXIMIANUS P F AVG. Busto com coroa radiada, drapeado e encouraçado de Maximiano, à direita.

Rev: VOT/XX dentro de coroa de louro.

Referência: http://www.coinproject.com/coin detail.php?coin=292788. Acesso em: 09/11/2021.

Seguindo esta tradição de emitir moedas para celebrar os aniversários de governo dos imperadores a cada cinco anos, em 369, Valentiniano I, pai de Graciano, comemorou seus cinco como augusto com a cunhagem de uma série de moedas que reforçava tal acontecimento. E em 373/4?, outra série foi lançada para celebrar seus dez anos como governante dos romanos: 


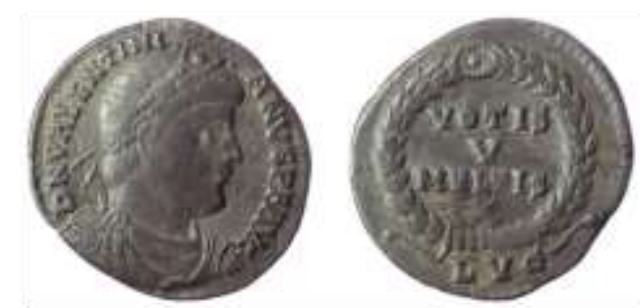

Imagem 4. Moeda de Valentiniano I. Comemoração de seus cinco anos como augusto.

Bronze, 368-369 d.C.

Anv.: D N VALENTINIANUS P F AVG. Busto com coroa de louro, drapeado e encouraçado de Valentiniano I, à direita.

Ver.: VOTIS/V/MULTIS/X dentro de coroa de louro; em baixo, LVG.

Referência: https://www.britishmuseum.org/collection/object/C B-1398. Acesso em: 09/11/2021.

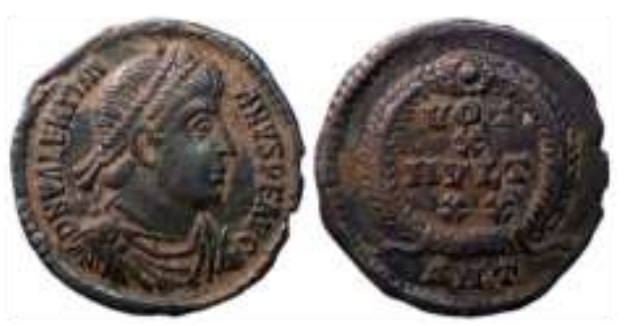

Imagem 5. Moeda de Valentiniano I. Comemoração de seus dez anos como augusto. Bronze, 373-374 d.C.

Anv.: D N VALENTINIANUS P F AVG. Busto com coroa de pérolas, drapeado e encouraçado de Valentiniano I, à direita.

Rev.: VOTIS/X/MULTIS/XX dentro de coroa de louro; em baixo, ANT.

Referência: https://www.britishmuseum.org/collection/object/C 1981-0909-8 Acesso em: 09/11/2021.

Valentiniano I morreu em 375. Havia reinado por onze anos. Por isso, não há numerários deste imperador que celebram seus quinze anos de governo. Já seu filho mais velho, Graciano, governou por cerca de dezesseis anos, tendo seus quinze anos como imperador romano comemorados entre os anos 381 e 382 com a emissão de uma série monetária da qual faz parte o numerário 163998 (MHN-RJ).

A exemplo de seu pai, e conforme uma tradição fortalecida na época do Império de Diocleciano e Maximiano, Graciano celebrou o aniversário de seu governo a cada cinco anos em numerários que exaltavam tal data e relembravam sua liderança frente aos romanos: 


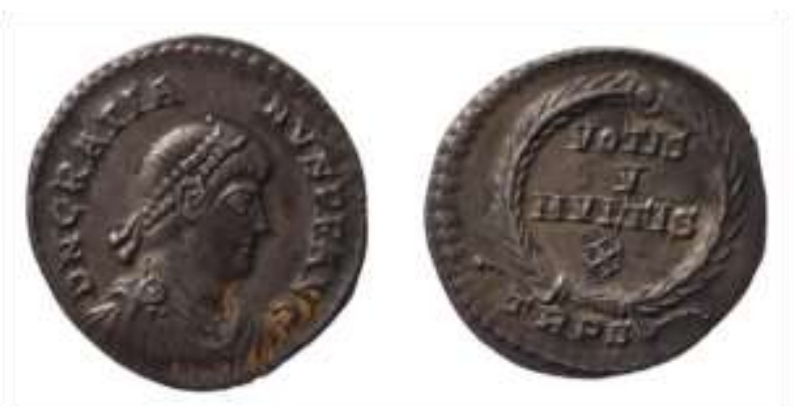

Imagem 6. Moeda de Graciano. Comemoração de seus cinco anos como augusto.

Bronze, 371-372 d.C.

Anv.: D N GRATIANVS P F AVG. Busto com coroa de pérolas, drapeado e encouraçado de Graciano, à direita.

Rev.: VOTIS/V/MULTIS/X dentro de coroa de louro; em baixo, TRPS.

Referência: https://www.britishmuseum.org/collection/object/C_B-957. Acesso em: 09/11/2021.

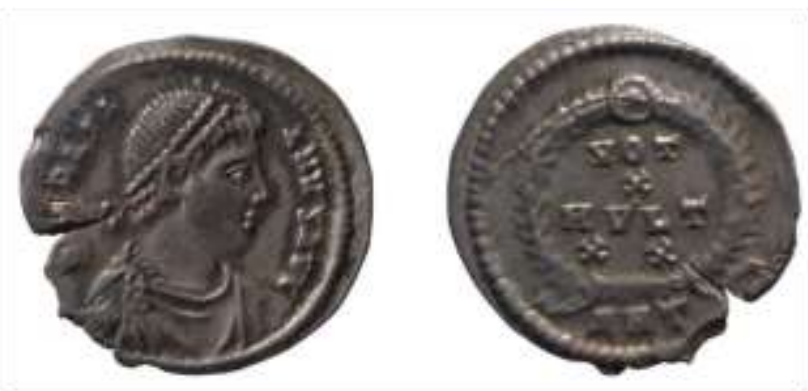

Imagem 7. Moeda de Graciano. Comemoração de seus dez anos como augusto, com votos para que alcance vinte anos de governo.

Bronze, Antioquia. 376-377 d.C.

Anv.: D N GRATIANVS P F AVG. Busto com coroa de pérolas, drapeado e encouraçado de Graciano, à direita.

Rev.: VOTIS/X/MULTIS/XX dentro de coroa de louro; em baixo,ANT.

Referência: https://www.britishmuseum.org/collection/object/C_1951-1115-97. Acesso em: 09/11/2021.
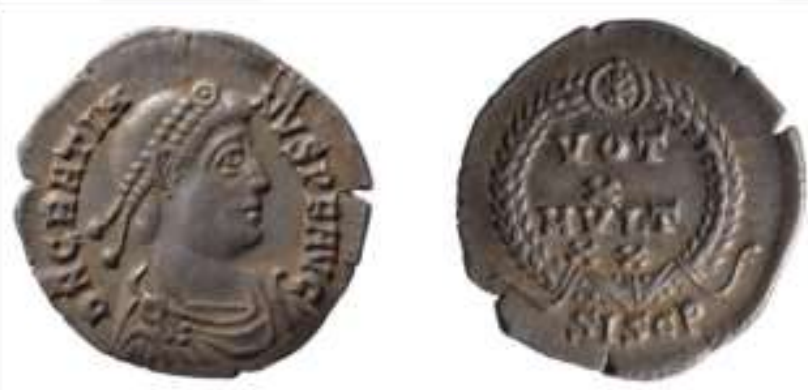

Imagem 8. Moeda de Graciano. Comemoração de seus dez anos como augusto, com votos para que alcance vinte anos de governo.

Bronze, Siscia (Panonia). 376-377 d.C. 
Anv.: D N GRATIANVS P F AVG. Busto com coroa de pérolas, drapeado e encouraçado de Graciano, à direita.

Rev.: VOTIS/X/MULTIS/XX dentro de coroa de louro; em baixo, SISCP.

Referência: https://www.britishmuseum.org/collection/object/C_1978-0643-28. Acesso em: 09/11/2021.

No reverso destas duas últimas moedas (Imagem 7 e Imagem 8) observa-se a legenda: VOT/X/MVLT/XX. Ou seja: "votos pelo aniversário de dez anos [do augusto como governante], que chegue aos vinte." Qual meu objetivo em apresentar duas moedas com a mesma informação? Possuir a mesma informação não significa que as moedas sejam iguais! Para citar apenas uma diferença entre os tipos ali batidos, noto que os traços que servem de "acabamento" para a coroa de louros do reverso da "Imagem 8", e que separam os demais tipos da informação sobre local em que a moeda foi gravada, são mais arredondados e longos do que os traços da outra moeda. Observo que o primeiro numerário foi cunhado em Antioquia (ANT), já o segundo, em Siscia, na Panonia (SISCP). Estes dados estão gravados nas moedas.

$\mathrm{Na}$ antiguidade romana, cada oficina monetária contava com um funcionário responsável por desenvolver o cunho com todas as informações solicitadas pela entidade emissora. Estes funcionários eram os esculpidores (scalptores) e eram formados nas casas monetárias que controlavam a emissões monetárias de uma série de oficinas (Carlan, Funari, 2012, p. 39). Esculpir uma moeda requeria, portanto, o trabalho artesanal de um operário que praticava suas habilidades manuais para realizar a representação dos tipos monetários. Sendo assim, por mais que ambas as moedas tivessem em seus reversos os mesmos tipos e proclamassem a mesma mensagem com relação à política imperial, a caligrafia, as imagens e os símbolos ali apresentados eram ligeiramente diferentes. Conforme Florenzano (2009, p. 50), mesmo cunhadas sob a autoridade do imperador, as moedas carregavam traços locais próprios. E isto fica evidente quando a Imagem 7 e a Imagem 8 são comparadas. Não só os reversos apresentavam disparidades. Os bustos de Gaciano batidos nos anversos destas moedas também portavam significativas dessemelhanças.

Para promover os quinze anos de governo de Graciano, destaco a moeda 163998 (MHNRJ) já apresentada no início deste artigo (Imagem 1) e documento motivador das reflexões propostas neste texto. Assim como os antigos gregos, os romanos consideravam as moedas como elementos de troca e peças comemorativas. Portanto, quando desejavam consagrar um fato à memória, representavam-no em suas moedas (Coimbra, 1957, p. 493).

Como seus antecessores, Graciano fez destas pequenas peças metálicas objetos importantes para divulgar mensagens que lembravam diariamente a amplitude do poder imperial e a utilidade pública do imperador. Seus aniversários como augusto ganharam os 
reversos de muitas séries monetárias. Mas, além desta celebração, quais outras mensagens as moedas votivas de Graciano propagavam?

Antes de passar à análise do anverso destas moedas, noto que, ainda no reverso das quatro moedas de Graciano destacadas neste artigo (Imagem 1, Imagem 6 a Imagem 8), as legendas estavam envoltas por uma coroa de louros. Outra característica herdade da tradição das moedas votivas, como é possível notar nas moedas da época tetrárquica e de Valentiniano I.

A coroa de louros simbolizava a vitória, por este motivo poderia ser chamada de coroa triunfal. Entre os antigos gregos, ela era oferecida aos atletas vencedores das Olimpíadas. Entre os romanos, generais e imperadores eram premiados com estas coroas quando venciam suas batalhas. Os imperadores também portavam uma coroa de louros em representações que destacavam seu poder militar e sua liderança frente aos romanos.

Paul Zanker (2005, p. 120) argumenta que a coroa de folhas da azinheira e do loureiro foram usadas por Augusto como sinal de homenagem e, rapidamente, passaram a ser utilizadas em diversos lugares e de variadas formas como símbolo de veneração ao governante. Por mais que se tratasse de simples ornamentos arquitetônicos, estas coroas carregavam consigo significados de homenagem e se converteram em atributos constantes de Augusto e dos demais imperadores.

No contexto de Graciano, em alguns dos reversos de suas moedas, a deusa Vitória foi cunhada coroando de louros o imperador (como exemplos, cito os numerários 163968, 163970 do MHN-RJ e 1994,0915.647 do Museu Britânico). Neste caso, a vitória imperial, representada pela coroa triunfal, ganhava o reforço discursivo da figura da divindade. No caso das moedas votivas, a coroa de louros circundava a legenda comemorativa, fornecendo ao documento mais um elemento que corroborava o poder imperial. Novamente, percebo a intenção de Graciano em se vincular a costumes já arraigados àquela cultura.

De acordo com Ney Chrysostomo da Costa (1969, p. 547), as moedas votivas foram muito populares, por isso foram cunhadas apenas em bronze. Sendo assim, possuíam baixo valor monetário e alcançavam, inclusive, as mãos de pessoas menos abastadas. Ou seja, a circulação destas moedas era muito maior do que a das peças de ouro e de prata. Os votos nelas batidos exaltavam a liderança imperial e poderiam inspirar a confiança dos súditos, construindo um compromisso entre o governante e seus governados. Mesmo que tal compromisso fosse uma idealização, esta elaboração discursiva era pertinente àquele contexto e integrava um conjunto de elementos constituintes da política imperial. 
Quanto ao reverso das moedas de Graciano, todos os documentos aqui apresentados possuíam a mesma legenda: D N GRATIANVS P F AVG. A identificação do imperador sob o qual estas peças foram cunhadas era clara, pois os documentos traziam o nome do governante (GRATIANVS) e, concomitantemente, anunciavam a autoridade emissora.

O nome do governante era precedido da abreviação do título Dominus Noster (DN), expressão traduzida para o português como "nosso senhor/proprietário", ou seja, "senhor/proprietário dos romanos". Andréia Tamanini (2015, p. 215-216) observa o duplo sentido do termo domus: local de habitação e pessoas ligadas por parentesco (biológico ou não). A esta notação, acrescento uma reflexão sobre o substantivo dominus. Entre os romanos, inicialmente este termo referia-se ao senhor ou proprietário dos escravos ("senhor/proprietário da casa" ("senhor/proprietário da domus"). O dominus era, então, o homem responsável pela manutenção de uma casa e das pessoas que nela viviam, fossem estes sujeitos ligados ao senhor por consanguinidade ou não. Este indivíduo detinha o pater famílias, sendo sua obrigação prover (econômica e socialmente) sua casa e aqueles ligados a ela. Em contrapartida, as pessoas sob seus cuidados deviam-lhe obediência.

Embora outros imperadores antes do período tetrárquico, como Aureliano (270-275), tenham utilizado este título para proclamar sua proteção a todos os romanos e, simultaneamente, a subordinação de todos ao seu poder, foi com Diocleciano e Maximiano que esta fórmula passou a ser definitivamente utilizada para designar o imperador.

Na moeda de Diocleciano apresentada neste artigo, observava-se a notação "IMP C" (imperator caesar) para se referir ao governante. Entretanto, ainda com este imperador e seu colega de poder, Maximiano, a fórmula "D N" substituiu "IMP C", como comprova a seguinte moeda:

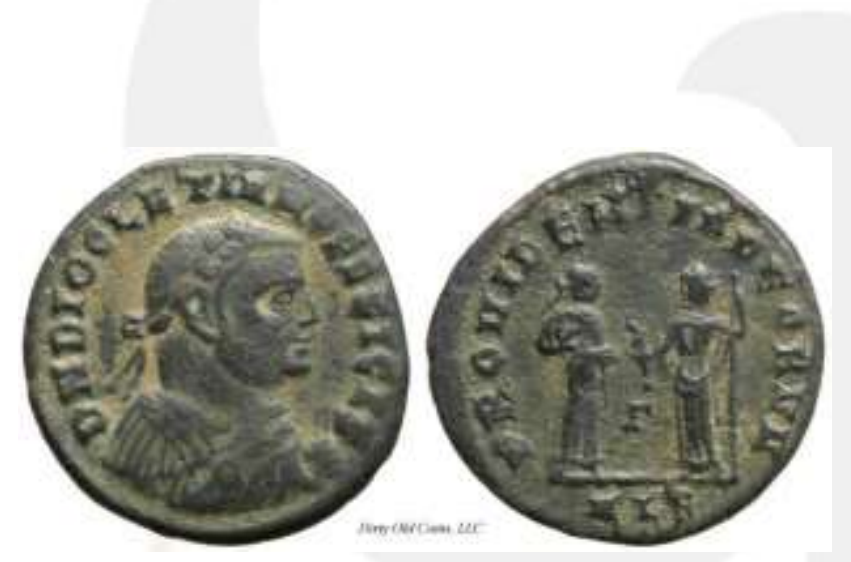

Imagem 9. Moeda de Diocleciano.

Bronze. 284-305 d.C.

Anv.: D N DIOCLETIANO FELICIS. Busto com coroa de louro, drapeado e encouraçado de Diocleciano, à direita. 
Rev.: PROVIDENTIA DEORVM. A Providência em pé à direita, estendendo a mão direita para Quies em pé, à esquerda, na mão direita segura um galho (para cima) e a esquerda apoia-se no cetro; entre as duas figuras, $\Gamma$; no exergo, ALE.

Referência: http://www.coinproject.com/coin_detail.php?coin=291670. Acesso em: 16/11/2021.

Durante a Tetrarquia, a formulação Dominus noster (D N) ganhou força, tornando-se comum a partir da dinastia constantiniana (Herrero Albiñana, 1994, p. 246). O fato de o imperador assumir a titulação dominus foi utilizado por muitos especialistas para marcar o fim da época do Principado e o início do Dominato do Império romano (Silva, Mendes, 2006, p. 193). Assim como seus antecessores, Graciano usou este título para corroborar seu papel como protetor dos romanos e, como contrapartida, agenciar o respeito dos seus súditos. Um fator que, somado a outros elementos discursivos, inclusive promovidos pelas moedas, sustentava sua atuação como comandante dos romanos, pois ampliava o pater família para toda àquela sociedade. E, certamente, um líder forte em seus territórios seria assim reconhecido por líderes estrangeiros.

Ainda nas legendas dos anversos das moedas de Graciano selecionadas para este artigo, o nome do imperador era seguido da abreviação "P F", pius felix ("piedoso e feliz"). Segundo Manuel José Rodríguez Gervás (1991, p. 79), a piedade (pietas) promovia a ligação entre os membros do Império romano. Por um lado, o governante nutria um sentimento de dever para com seus súditos, enquanto estes mantinham-se leais a quem governava pois necessitavam dos cuidados do seu líder. Observo, então, que a união promovida por esta virtude era benéfica para as partes envolvidas nesta relação e seguia a noção de proteção concedida pelo poder imperial aos seus governados, reforçando a ideia já contida no título dominus.

A felicidade era uma virtude pública, sendo assim, precisava ser celebrada publicamente. Celebração, esta, promovida pelas mensagens que circulavam através das peças monetárias. Conforme Rodríguez Gervás (1991, p. 79), a virtude da "felicidade" era a que mais se repetia nas moedas romanas. Esta virtude estava ligada a outras duas: fortuna e paz. Elas concretizavam em palavras aspectos militares dos imperadores e a felicidade era consequência da proteção advinda da fortuna. A felicidade era, portanto, o sinal de ajuda dos deuses aos imperadores (Rodríguez Gervás, 1991, p. 79). Observo, então, que a ligação divina que o governante do Império possuía era um dos suportes teóricos da manutenção do seu poder. Afinal, quem iria contradizer aquele indivíduo escolhido pelos deuses?

Esta relação divina que o imperador mantinha era, também, reforçada pelo título honorífico augustus (augusto), presente nas moedas de Graciano e de seus antecessores por meio da abreviação "AVG”. Esta titulação destacava o caráter divino do imperador, uma vez 
que o termo augustus, em português, significa "divino", "sagrado". O primeiro governante romano carregar esta algunha foi Otávio, que fez deste título seu nome como princeps: Augusto. De forma resumida e eficiente, Zanker (2005) traçou o caminho percorrido por Augusto para divinizar seu pai adotivo, Júlio César, criando o culto a Divus Iulius. Em seguida, Augusto proclamou-se Divi filius, filho do divinizado (Zanker, 2005, p. 54-56). A partir deste governante, todos os imperadores passaram a portar a titulação "augusto", nutrindo um discurso que estreitava os laços entre os governantes romanos e os deuses.

Alessandra Bravi afirma que "a natureza divina dos imperadores ainda está entrelaçada com a esfera intensamente social das ideologias políticas" (Bravi, 2011, p. 154). Logo, o aspecto divino do governante, imprescindível para o culto imperial, necessitava ser constantemente reelaborado, reproduzido e anunciado para que fosse aceito socialmente e passasse a integrar a cultura daquela gente. Sendo o culto imperial uma forma de conexão e um elemento de coesão, era significativo que ele se apresentasse de uma maneira uniforme (Porto, 2018, p. 141) e de fácil compreensão a todos. Para esta análise, destaco os estudos de Florenzano, Angela Maria Gianeze Ribeiro e Viviana Lo Monaco, com os quais concordo:

Com relação ao uso e à difusão da moeda romana, temos também que lembrar que um Império tão grande, era preciso construir algum tipo de identidade que reunisse a todos e que os subjugasse ao poder central. Não há dúvidas de que a moeda tinha um papel importante na construção desta identidade. Em primeiro lugar, por ser um instrumento de mediação de riqueza e de troca promovia o relacionamento de indivíduos diferentes que por meio dela tinham um canal que os igualava, E em segundo lugar, porque divulgava os feitos do homem mais poderoso do Império sob a autoridade de quem a vida de todos era regida. (Florenzano; Gianeze; Lo Monaco, 2015, p. 18)

As autoras ressaltam a importância das moedas na elaboração de uma identidade romana frente à imensidão do Império, uma vez que a igualdade gerada pelas moedas como um "instrumento de mediação da riqueza" e como um espaço de anúncio das ações imperiais unificava aquela gente em torno noções reconhecidas por todos. Entre estas ações, saliento a celebração dos aniversários de governo do imperador. Estes marcos festejavam a longevidade de tal governo e relembravam aos governados quem comandava aquela sociedade.

Por ser um documento oficial, que almejava esta uniformização da mensagem do culto imperial, a cunhagem das moedas deveria empregar cânones previamente definidos (Greene, 1986, p. 50). E os tipos gravados nestes documentos deveriam seguir convenções sociais, uma vez que precisavam ser facilmente lidos e entendidos pelo público que tinha acesso às moedas.

Nesta conjuntura, a legenda "D N GRATIANVS P F AVG”, estava pautada em princípios inerentes à tradição romana e congregava dois elementos que elaboravam e 
propagavam a força divina de Graciano: a virtude da felicidade (P F) e o a titulação augustus. Uniu-se a estes elementos o título dominus noster e a virtude da piedade que construíam a noção de que o imperador era o protetor dos romanos. Esta legenda, por sua vez, circundava o busto de Graciano, que portava o diadema de pérolas, uma das três insígnias imperiais, juntamente com o manto púrpuro e a labarum. O diadema, portanto, identificava o caráter imperial daquele que o usava.

Zanker (2005, p. 78) esclarece que, com Augusto, a estética se colocou a serviço da política e defende que:

Diferente das moedas carregadas e de difícil leitura do último período da república, [a partir de Augusto] as novas imagens das moedas chamariam a atenção por sua clareza e simplicidade [...]. Estas imagens eram compreensíveis inclusive sem comentário algum. (Zanker, 2005, p. 78)

É certo que, até este momento do artigo, propus uma leitura das legendas dos anversos e dos reversos das moedas imperiais. Todavia, a compreensão da imagem de Graciano, com sua indumentária imperial, faz-se mister para uma leitura mais ampla do documento. Noto que, durante a antiguidade romana, grande maioria da população não sabia ler. Quando analisadas apenas as imagens das moedas votivas de Graciano, observo dois elementos: a coroa de louros (no reverso) e o busto imperial (no anverso). A leitura apenas destas imagens, embora ofereça uma ideia parcial da mensagem requerida por Graciano, aproxima-se daquela feita pelos iletrados da época. Mesmo ciente disso, creio que seja importante elaborar meus argumentos sobre os demais tipos presentes nestes documentos para contemplar vários aspectos da cultura, da tradição e da política romanas.

Arnaud Pascal (s/d, p. 195) considera o anverso a parte mais importante das moedas, afinal, nele estava registrado a efigie de quem ordenou a cunhagem do documento, juntamente com seu título, no caso dos numerários de Graciano, AVG. Sobre a mensagem apreendida através de uma imagem, Donis Dondis (1997, p. 184) alude que a comunicação pictórica deve ser simples e realista para ser entendida pelos grupos que possuem baixo índice de alfabetização. Sendo assim, no que se refere às imagens, desenhar um indivíduo e identificá-lo com os aparatos que o diferenciavam dos demais romanos era uma estratégia primordial para difundir a noção da supremacia imperial. Neste caso, a reforma monetária de Nero (54 - 68), realizada em 64, que aprimorou a qualidade artística e o realismo das representações das imagens das moedas, foi um passo importante para a tradição da cunhagem das moedas romanas. 
Reforço a amplitude do Império romano e a possibilidade remota que todos os governados tinham de ver o imperador em pessoa. Nesta conjuntura, novamente, a moeda servia para a identificação do governante e, especialmente, para recordar aos súditos imperais que eles tinham um comandante, coroado e destacado dos demais sujeitos daquela sociedade. E a cada cinco anos, as séries de moedas votivas, comemoravam a duração do governo deste líder.

Graciano, enfim, associou-se a todos estes elementos tradicionais quando lançou mão da cunhagem de suas moedas votivas. Com elas, um discurso de supremacia do poder imperial e da utilidade pública do governante, pululava pelas terras romanas e para além, delas.

\section{Considerações finais}

Em conjunto, as imagens e as abreviações batidas nas legendas dos reversos e dos anversos das moedas de Graciano, carregavam elaborações discursivas atreladas a tradições romanas que fortaleciam o poder imperial e atestavam a importância pública do governante. Embora hoje em dia não seja possível compreender as moedas como instrumentos de comunicação entre pessoas distantes, durante a antiguidade, estas peças de metal anunciavam uma mensagem unificada para terras distantes submetidas ao poder imperial e, também, para lugares além destas fronteiras.

As leituras oferecidas por mim neste artigo, mostram o quanto as palavras e a imagem estavam relacionadas no estudo das antigas moedas romanas. Mesmo sendo possível identificar-se o personagem cunhado nas moedas como o um imperador e comandante romano apenas através da imagem, a leitura em conjunto dos tipos esclarece pormenores da política imperial de Graciano. Através deste diálogo, entendo as interações construídas e propostas por este imperador para assegurar seu papel naquele contexto.

Noto que as moedas romanas eram peças muito pequenas, sendo assim, as mensagens nelas cunhadas deveriam se apresentar de forma resumida e simples, nem por isso, a autoridade emissora ignorava aquele pequeno espaço de divulgação do seu poder. Mesmo no caso das moedas votivas, todas cunhadas em bronze, ou seja, em peças de menor valor monetário, Graciano fez destes documentos elementos de legitimação de sua utilidade pública.

\section{Referências bibliográficas}

BRAVI, Alessandra. Immaginario dell'apoteosi e politiche imperiali a Roma tra Cesare e i Flavi. In: ANDREU, Javier; ESPINOSA, David; PASTOR, Simone (coords.). Mors omnibus 
instat: Aspectos arqueológicos, epigráficos y rituales de la muerte en el Occidente Romano. Madrid: Liceus, 2011.

CARLAN, Cláudio Umpierre; FUNARI, Pedro Paulo Abreu. Moedas: a numismática e o estudo da História. São Paulo: Annablume, 2012 (Coleção História e Arqueologia em movimento).

COIMBRA, Álvaro da Veiga. Questões de Numismática (VIII). Revista de História, vol. 15, n. 32, p. 491-538, dezembro/1957. DOI: 10.11606/issn.2316-9141.rh.1957.106230

COSTA, Ney Chrysostomo da. Dicionário de numismática. Porto Alegre: Livraria Sulina Editora, 1969.

COSTILHES, Alain Jean. O que é numismática. São Paulo: Editora Brasiliense, s/d. (Coleção Primeiros Passos)

DONDIS, Donis A. A sintaxe da linguagem visual. Tradução Jefferson Luiz Camargo. $2^{\mathrm{a}}$ ed., São Paulo: Martins Fontes, 1997.

FLORENZANO, Maria Beatriz Borba; RIBEIRO, Angela Maria Gianeze; LO MONACO, Viviana. A coleção de moedas romanas da Universidade de São Paulo: Museu Paulista, Museu de Arqueologia e Etnologia. São Paulo: MAE-USP, 2015.

FLORENZANO, Maria Beatriz Borba. Entre o artefato e o texto: a moeda no mundo antigo.

XI Congresso da Sociedade de Arqueologia Brasileira, 2001, Rio de Janeiro. SAB 2001 A arqueologia no novo milênio. Rio de Janeiro: Sociedade de Arqueologia Brasileira, 2001. p. 61 73.

FLORENZANO, Maria Beatriz Borba; VIANNA, Salvador Teixeira Werneck; CASTRO, Maurício Barros de. Faces da moeda. vol. 1, São Paulo: Editora Olhares, 2009.

FUNARI, Pedro Paulo A.; HALL, Martin; JONES, Siân. Historical Archaeology: back from the Edge. London: Routledge, 1999.

GREENE, Kevin. The Archeology of the Roman economy. London: Bastford, 1986.

HERRERO ALBIÑANA, Carmen. Introducción a la numismática antigua (Grecia e Roma). Madrid: Editorial Complutense, 1994.

MATTINGLY, Harold; SUTHERLAND, C.H.V.; CARSON, R.A.G. (eds.). The Roman Imperial Conaige, vol. IX: Valentinian I - Theodosius I. London: Spink and Son, 1951. (RIC IX)

PORTO, Vagner Carvalheiro. Imagens monetárias na Judéia/Palestina sob dominação romana (Tomo I). Tese apresentada ao Programa de Pós-Graduação em Arquelogia do Museu de Arqueologia e Etnologia da Universidade de São Paulo, 2007.

PORTO, Vagner Carvalheiro. O culto imperial e as moedas do Império Romano. Phoînix, Rio de Janeiro, vol. 24, n. 1, p. 138-154, 2018.

RODRÍGUEZ GERVÁS, Manuel J. Propaganda política y opinión pública en los panegíricos latinos del Bajo Imperio. Salamanca: Ediciones Universidad de Salamanca, 1991. SILVA, Gilvan Ventura da; MENDES, Norma Musco. Diocleciano e Constantino: a construção do Dominato. In: SILVA, Gilvan Ventura da; MENDES, Norma Musco (org.). Repensando o Império Romano: perspectiva socioeconômica política e cultural. Rio de Janeiro: Mauad; Vitória, ES: EDUFES, 2006, p. 193-221.

TAMANINI, Andréia. Domus Liviae: família, gênero e identidade na gens imperial. Ágora Estudos Clássicos em Debate. n.17, p. 215-228, 2015, 215-228. Disponível em: http://www2.dlc.ua.pt/classicos/17/9.domusLiuiae.pdf. Acesso em: 16/11/2021.

ZANKER, Paul. Augusto y el poder de las imágenes. Versión española de Pablo Diener Ojeda. Madrid: Alianza Editorial, 2005. 


\section{Páginas de internet (documentos)}

Coin Project: http://www.coinproject.com/. Acesso em: 09/11/2021.

British Museum: https://www.britishmuseum.org/collection. Acesso em: 09/11/2021. 